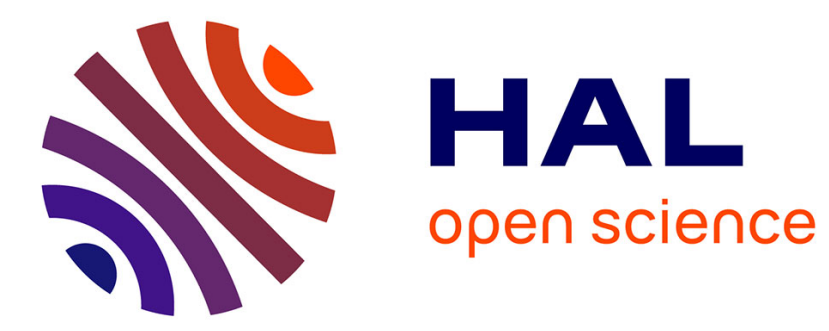

\title{
Hybrid Analytical Model Coupling Laplace's Equation and Reluctance Network for Electrical Machines
}

Sara Bazhar, Julien Fontchastagner, Noureddine Takorabet, Nicolas Labbe

\section{To cite this version:}

Sara Bazhar, Julien Fontchastagner, Noureddine Takorabet, Nicolas Labbe. Hybrid Analytical Model Coupling Laplace's Equation and Reluctance Network for Electrical Machines. IEEE Transactions on Magnetics, 2017, 53 (6), pp.8102304. 10.1109/TMAG.2017.2654966 . hal-01631132

\section{HAL Id: hal-01631132 \\ https://hal.univ-lorraine.fr/hal-01631132}

Submitted on 8 Nov 2017

HAL is a multi-disciplinary open access archive for the deposit and dissemination of scientific research documents, whether they are published or not. The documents may come from teaching and research institutions in France or abroad, or from public or private research centers.
L'archive ouverte pluridisciplinaire HAL, est destinée au dépôt et à la diffusion de documents scientifiques de niveau recherche, publiés ou non, émanant des établissements d'enseignement et de recherche français ou étrangers, des laboratoires publics ou privés. 


\title{
Hybrid Analytical Model Coupling Laplace's Equation and Reluctance Network for Electrical Machines
}

\author{
S. Bazhar ${ }^{1,2}$, J. Fontchastagner ${ }^{1}$, N. Takorabet ${ }^{1}$, and N. Labbe ${ }^{2}$ \\ ${ }^{1}$ Université de Lorraine, 54516 Nancy, France \\ ${ }^{2}$ Valeo Electrical Systems, 38291 Saint-Quentin-Fallavier, France
}

This paper presents a hybrid magnetic model combining reluctance network and Laplace's equation resolution using magnetic vector potential in the air gap. The coupling of the two models is performed by introducing fictive equivalent magnetomotive forces in the air gap. The model is applied to the study of dc machines used as a starter in automotive application. Good results are obtained compared with finite-element model and experimental measurements.

Index Terms - Analytical formulation, hybrid magnetic model, reluctance network (RN).

\section{INTRODUCTION}

A NALYTICAL models based on the resolution of the Laplace equation using the method of separation of variables have been developed for the modeling of electrical machines as in [1]. These models are accurate and fast but do not consider the nonlinear aspects of ferromagnetic materials. To improve this method, the saturation of the iron yoke can be included by making a hybrid model between tinite elements (FEs) in the iron parts and the Laplace equation in the air gap as presented in [2]. This FE hybrid model showed its effectiveness through its use in a geometrical optimization process in [3]. However, in some cases, we need to model the complete geometry of the studied device, so the FE part of the model becomes time-consuming. An alternate way consists of introducing reluctance network ( $\mathrm{RN}$ ) models in ferromagnetic parts of electrical machines instead of modeling them by FE method [4], [5]. In these RN hybrid models, the air gap is modeled by a set of reluctances calculated from the analytical expression of the magnetic potential vector. This kind of RN hybrid model makes the model complex to develop. Indeed, each air-gap terminal of the boundary stator or rotor reluctance is connected to the whole other air-gap terminals, this method needs a high number of airgap reluctances to consider the rotation of the machine. The coupling between the stator and rotor is then made by circuit connections.

In this paper, we present an alternate method of coupling the reluctances of the stator and the rotor with a set of magnetomotive forces (MMFs) which depend on these reluctance lluxes. With this method and thanks to the expression of these MMFs depending on all stator and rotor boundaries reluctance fluxes, the number of circuit connections is reduced to one reference point. This point is arbitrarily chosen in the air gap, to link the different MMFs.

This hybrid model reduces the number of air-gap connections and simplifies the model, making it faster. The developed

Manuscript received November 17, 2016; revised January 14, 2017; accepted January 15, 2017. Date of publication January 17, 2017; date of current version May 26, 2017. Corresponding author: S. Bazhar (e-mail: sara.bazhar@univ-lorraine.fr).

Color versions of onc or more of the figures in this paper are availahle online at http://ieeexplore.ieee.org.

Digital Objecl Identificr 10.1109/TMAG.2017.2654966

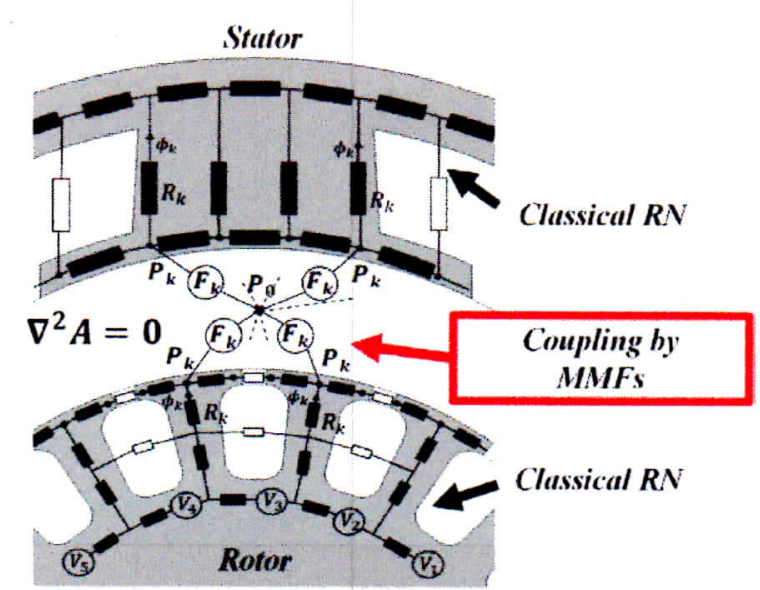

Fig. 1. Principle of the hybrid model and presentation of air-gap MMFs.

model is applied on a dc machine. Based on this example, the principle of the MMFs coupling is validated thanks to corresponding finite-element models (FEMs) and measurements.

\section{AIR-GAP MODELING PRINCIPLE}

The principle of the hybrid model is applied to a dc machine in 2-D, as shown in Fig. 1. In this model, the air and the iron yoke of the rotor and stator are modeled by a RN, while the air gap is modeled by a set of MMFs $F_{k}$. These air-gap MMFs are calculated from the terminal $P_{k}$ of the reluctance $R_{k}$ to the reference point $P_{0}$. Indeed, this reference point $P_{0}$ is a zero point potential arbitrarily chosen in the air gap. In the following, we will show how these MMFs are calculated from the resolution of the Laplace equation.

\section{A. Modeling of Air-Gap Magnetomotive Forces}

The MMF is a magnetic potential difference calculated between two points from $P_{k}$ to $P_{0}$, it is therefore expressed using the magnetic field $\boldsymbol{H}$

$$
F=\int_{P_{k}}^{P_{0}} \boldsymbol{H} \cdot d \boldsymbol{l}=F_{r}+F_{\theta} .
$$

The MMF can be expressed as a sum of two terms depending on the radial and the tangential components of the magnetic 


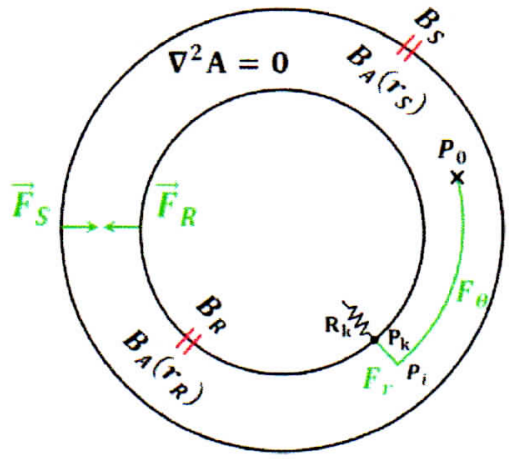

Fig. 2. MMFs calculation principle between each reluctance in the boundary of the air gap and the reference point.

field (as shown in Fig. 2)

$$
\left\{\begin{array}{l}
F_{r}=\int_{r_{k}}^{r_{i}} H_{r} d r=\frac{1}{\mu_{0}} \int_{r_{k}}^{r_{i}} \frac{1}{r} \frac{\partial A_{z}(r, 0)}{\partial \theta} d r \\
F_{\theta}=\int_{\theta_{i}}^{\theta_{0}} H_{\theta} r_{0} d \theta=-\frac{1}{\mu_{0}} \int_{\theta_{i}}^{\theta_{0}} \frac{\partial A_{z}(r, 0)}{\partial r} r_{0} d \theta
\end{array}\right.
$$

where $A_{z}$ is the axial component of the magnetic vector potential (MVP).

In this model, the coupling between the stator and the rotor is not introduced by circuit connections as shown in Fig. 1, but it lies in the global expressions of the MMFs. Indeed, each MMF depends on the MVP as in (2). The calculation of the MVP by the variable separation method needs to use the boundaries' conditions on both stator and rotor radii $r_{\mathrm{si}}$ and $r_{\mathrm{re}}$. These boundaries' conditions use the fluxes $\phi_{S}$ and $\phi_{R}$ provided by the RNs of the stator, respectively.

The MMFs $\left[\boldsymbol{F}_{S}\right]$ and $\left[\boldsymbol{F}_{\boldsymbol{R}}\right]$, respectively, connected to the stator and the rotor, can be expressed in terms of vector of lluxes $\left[\phi_{S}\right]$ and $\left[\phi_{R}\right]$ as follows:

$$
\left[\begin{array}{l}
{\left[F_{S}\right]} \\
{\left[F_{R}\right]}
\end{array}\right]=\left[\begin{array}{l}
{\left[K_{S S}\right]\left[K_{S R}\right]} \\
{\left[K_{R S}\right]\left[K_{R R}\right]}
\end{array}\right]\left[\begin{array}{l}
{\left[\phi_{S}\right]} \\
{\left[\phi_{R}\right]}
\end{array}\right] .
$$

$\left[\boldsymbol{K}_{S S}\right],\left[\boldsymbol{K}_{S R}\right],\left[\boldsymbol{K}_{\boldsymbol{R} S}\right],\left[\boldsymbol{K}_{\boldsymbol{R} R}\right]$ are matrices determined by using the expression of the MVP in the air gap. These matrices have the same unit as reluctances, but do not correspond to fixed flux tubes. The above matrices are determined using the definition of the MMFs (2) and the resolution of the I,aplace equation in the air gap which is developed in the following.

\section{B. Laplace Equation Resolution}

The air-gap MVP $A_{z}$ is determined by solving the Laplace equation (in polar coordinates) using the method of separation of variables, as explained in [6]. The general expression of the solution is given by

$$
\begin{aligned}
A_{z}(r, \theta)= & \left(a_{0}+b_{0} \ln (r)\right)+\sum_{n=1}^{N_{h}}\left(\alpha_{1 n} r^{n}+\alpha_{2 n} r^{-n}\right) \cos (n p \theta) \\
& +\left(\beta_{1 n} r^{n}+\beta_{2 n} r^{-n}\right) \sin (n p \theta)
\end{aligned}
$$

where $N_{h}$ is the number of harmonics considered and $p$ means the periodicity coefficient. Both $a_{0}$ and $b_{0}$ are zero due to the periodicity of the solution. $\alpha_{1 n}, \alpha_{2 n}, \beta_{1 n}, \beta_{2 n}$ are unknown coefificients that can be determined using the boundary conditions on $r=r_{\mathrm{si}}$ and $r=r_{\mathrm{re}}$. On these boundaries, the normal flux density $B_{r}$ is considered using the fluxes $\phi_{S}$ and $\phi_{R}$ provided by the RN. It is assumed that the tangential flux density $B_{\theta}$ is zero at both boundaries.

\section{Boundaries' Conditions}

From each terminal $P_{k}$ belonging to the air-gap boundaries connected to a reluctance $R_{k}$, flows a flux $\phi_{k}$. According to $\mathrm{RN}$ principle, the flux density corresponding to each reluctance is constant over the cross section of the flux tube

$$
B_{r, k}(\theta)=\frac{\phi_{k}}{S_{k}} v_{k}(\theta)
$$

where

$B_{r, k}$ corresponds to the normal flux density due to the stator or rotor reluctances;

$v_{k} \quad$ support function of the flux density created by the reluctance $R_{k}$, noticed $\nu_{k}^{S}$, and $\nu_{k}^{R}$ when defined to the stator and rotor boundaries, respectively;

$S_{k} \quad$ cross-sectional surface of the corresponding flux tube, denoted $S_{k}^{S}$ and $S_{k}^{R}$ when defined in the stator and rotor boundaries, respectively.

Using the superposition principle in the air gap, the total flux density on the boundaries $r=r_{\mathrm{si}}$ and $r=r_{\mathrm{re}}$ is expressed as the sum of elementary flux densities created by the fluxes of the different reluctances such that

$$
B_{r}\left(r_{\mathrm{si}}, \theta\right)=\sum_{k=1}^{N_{S}} \frac{\phi_{k}^{S}}{S_{k}^{S}} v_{k}^{S}(\theta) ; \quad B_{r}\left(r_{\mathrm{re}}, \theta\right)=\sum_{k=1}^{N_{R}} \frac{\phi_{k}^{R}}{S_{k}^{R}} v_{k}^{R}(\theta)
$$

$N_{S}$ and $N_{R}$ are, respectively, the numbers of the reluctances in the stator and the rotor boundaries. $\phi_{k}^{S}$ and $\phi_{k}^{R}$ are the elementary fluxes of the vectors $\left[\phi_{S}\right]$ and $\left[\phi_{R}\right]$ used in (3).

To find the unknown coelficients of the MVP according to (4), the general support function is expressed by its spectral decomposition

$$
\nu_{k}(\theta)=\frac{w_{k}}{2 \pi}+\sum_{n=1}^{N_{h}} C_{n}(k) \cos (n p \theta)+D_{n}(k) \sin (n p \theta)
$$

with

$$
\left\{\begin{aligned}
& C_{n}(k)=\frac{2}{2 \pi n}( \sin \left(n\left(\theta_{k}+\theta+\frac{w_{k}}{2}\right)\right) \\
&-\left.\sin \left(n\left(\theta_{k}+\theta-\frac{w_{k}}{2}\right)\right)\right) \\
& D_{n}(k)=\frac{2}{2 \pi n}\left(\cos \left(n\left(\theta_{k}+\theta-\frac{w_{k}}{2}\right)\right)\right. \\
&\left.-\cos \left(n\left(\theta_{k}+\theta+\frac{w_{k}}{2}\right)\right)\right)
\end{aligned}\right.
$$

where

$\theta_{k} \quad$ position of the corresponding reluctance;

$w_{k}$ width of the flux tube.

The boundaries' conditions are expressed as follows:

$$
\left\{\begin{array}{l}
B_{r}\left(r_{\mathrm{re}}, \theta\right)=\left(1 / r \cdot \partial_{H} A_{z}(r, \theta)\right)_{r_{\mathrm{re}}} \\
B_{r}\left(r_{\mathrm{si}}, \theta\right)=\left(1 / r \cdot \partial_{\theta} A_{z}(r, \theta)\right)_{r_{\mathrm{si}}} .
\end{array}\right.
$$


From (4), the nurmal llux density can be expressed as

$$
\begin{aligned}
\frac{1}{r} \partial_{\theta} A_{z}(r, \theta)= & \sum_{n=1}^{N_{h}}-n p\left(\alpha_{1 n} r^{n-1}+\alpha_{2 n} r^{-n-1}\right) \sin (n p \theta) \\
& +n p\left(\beta_{1 n} r^{n-1}+\beta_{2 n} r^{-n-1}\right) \cos (n p \theta) .
\end{aligned}
$$

Combining (5), (7), and (10), the four coefficients $\left(\alpha_{1 n}, \alpha_{2 n}\right.$, $\left.\beta_{1 n}, \beta_{2 n}\right)$ are determined for each harmonic and gathered in the vectors

$$
\left\{\begin{array}{l}
{\left[\alpha_{1}\right]=\left[L_{1}\right]\left[\phi_{R}\right]+\left[L_{2}\right]\left[\phi_{S}\right]} \\
{\left[\alpha_{2}\right]=\left[M_{1}\right]\left[\phi_{R}\right]+\left[M_{2}\right]\left[\phi_{S}\right]} \\
{\left[\beta_{1}\right]=\left[N_{1}\right]\left[\phi_{R}\right]+\left[N_{2}\right]\left[\phi_{S}\right]} \\
{\left[\beta_{2}\right]=\left[O_{1}\right]\left[\phi_{R}\right]+\left[O_{2}\right]\left[\phi_{S}\right]}
\end{array}\right.
$$

where $\left[L_{1}\right],\left[L_{2}\right],\left[M_{1}\right],\left[M_{2}\right],\left[N_{1}\right],\left[N_{2}\right],\left[O_{1}\right]$, and $\left[O_{2}\right]$ are matrices depending on the geometrical parameters of the considered machine.

According to (11), the air-gap MVP $A_{z}(r, \theta)$ is determined with the lluxes $\left[\phi_{R}\right]$ and $\left[\phi_{S}\right]$ provided by the RNs. In the following, the calculation of MMFs is detailed.

\section{Magnetomotive Forces Calculation}

According to (2) and (4), the MMFs $F_{r}$ and $F_{\theta}$ can be expressed as

$$
\begin{aligned}
F_{r, k}= & \frac{1}{\mu_{0}} \sum_{n=1}^{N_{h}}-p\left(\begin{array}{l}
\alpha_{1 n}\left(r_{i}^{n}-r_{k}^{n}\right) \\
-\alpha_{2 n}\left(r_{i}^{-n}-r_{k}^{-n}\right)
\end{array}\right) \sin \left(n p \theta_{k}\right) \\
& +p\left(\begin{array}{l}
\beta_{1 n}\left(r_{i}^{n}-r_{k}^{n}\right) \\
-\beta_{2 n}\left(r_{i}^{-n}-r_{k}^{-n}\right)
\end{array}\right) \cos \left(n p \theta_{k}\right) \\
F_{\theta, k}= & -\frac{1}{\mu_{0}} \sum_{n=1}^{N_{h}} \frac{1}{p} \cdot\left(\begin{array}{l}
\alpha_{1 n} r_{0}^{n} \\
-\alpha_{2 n} r_{0}^{-n}
\end{array}\right)\left(\begin{array}{l}
\sin \left(n p \theta_{0}\right) \\
-\sin \left(n p \theta_{i}\right)
\end{array}\right) \\
& -\frac{1}{p} \cdot\left(\begin{array}{l}
\beta_{1 n} r_{0}^{n} \\
-\beta_{2 n} r_{0}^{-n}
\end{array}\right)\left(\begin{array}{l}
\cos \left(n p \theta_{0}\right) \\
-\cos \left(n p \theta_{i}\right)
\end{array}\right) .
\end{aligned}
$$

Introducing (11) in the two previous equations, normal and tangential MMFs are expressed in terms of rotor and stator fluxes $\phi_{S}$ and $\phi_{R}$

$$
F=f\left(\phi_{R}, \phi_{S}\right) .
$$

Finally, using the definition (3), the expressions of the matrices $\left[K_{S S}\right],\left[K_{S R}\right],\left[K_{R S}\right],\left[K_{R R}\right]$ are identified.

As explained in Section II-A, the coupling method developed in this paper does not depend on any circuit connection, but lies on the global expression of the air-gap MMFs. This approach allows us to avoid the complexity and the drawbacks of the classical RNs.

Thanks to this model, the rotor movement does not introduce any problem in the simulation of the machine and the torque waveforms can be easily determined.

\section{E. Torque Calculation by Maxwell Stress Tensor}

Usually in RNs, the torque is calculated with virtual works principle using the derivation of the coenergy. In the developed hybrid model, normal and tangential components of the air-gap flux density are known through MVP $A_{z}$. Therefore, Maxwell

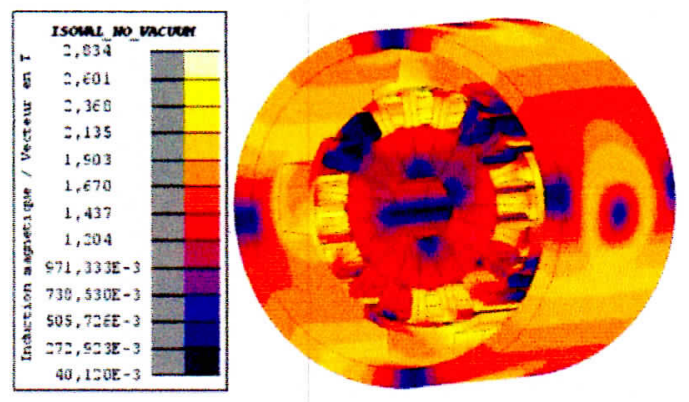

Fig. 3. 3-D FEM and field map of the dc machine.

TABLE I

Geometrical Parameters of the Machine

\begin{tabular}{ll}
\hline Rotor outer radius $\rightarrow 24,8510^{-3} \mathrm{~m}$ & Rotor stack length $\rightarrow 3510^{-3} \mathrm{~m}$ \\
Air-gap thickness $\rightarrow 0,6510^{-3} \mathrm{~m}$ & Poles axial length $\rightarrow 30,510^{-3} \mathrm{~m}$ \\
Machine outer radius $\rightarrow 3810^{-3} \mathrm{~m}$ & Stator yoke length $\rightarrow 6010^{-3} \mathrm{~m}$ \\
\hline
\end{tabular}

stress tensor can be used on a circular path of radius $r_{m}$ in the air gap to evaluate the electromagnetic torque

$$
T_{e m}=\frac{r_{m}^{2} L_{z}}{\mu_{0}} \int_{0}^{2 \pi} B_{\theta}\left(r_{m}, \theta\right) B_{r}\left(r_{m}, \theta\right) d \theta
$$

with $L_{z}$ the stack length of the machine.

The normal and tangential components of the flux density are expressed in terms of MVP in which coefficients $\alpha_{1 n}, \alpha_{2 n}, \beta_{1 n}$, and $\beta_{2 n}$ are depending on the fluxes $\left[\phi_{R}\right]$ and $\left[\phi_{S}\right]$. The use of separation of variables method enables us to express all the quantities in terms of their spectral decomposition cocfficient. By replacing the integral $\int_{0}^{2 \pi} B_{0} B_{r} d \theta$, the final expression of the toryue is then simplified to

$$
T_{e m}=\frac{2 \pi L_{z}}{\mu_{0}} \sum_{n=0}^{N_{h}}-n^{2} p\left(\beta_{2 n} \alpha_{1 n}-\beta_{1 n} \alpha_{2 n}\right) .
$$

\section{VALIDATION OF THE MODEL}

The model is validated by comparing the obtained magnetic characteristics to the corresponding 2-D FEM. The modeled machine is a 4-pole 19-slot dc series motor used in automotive starters. In this application, the machine is subjected to very high saturation levels far exceeding $2 \mathrm{~T}$ in a magnetic material with a saturation magnetization $2 \mathrm{~T}$ as shown in Fig. 3. The geometrical parameters of the machine are listed in Table I.

The 2-D FE mesh of the machine is shown in Fig. 4, where the yellow parts represent windings, the white parts vacuum, and the gray parts the stator and rotor iron core.

The proposed hybrid model is tested under several conditions in order to validate the accuracy of the MMFs coupling method. First, the flux density waveforms under the stator poles of the dc series machine given by full FEM, and hybrid model is shown in Fig. 5. It can he seen on this figure, that the blue curve provided by the hybrid model and the red curve given by FEM have the same shape. In fact, the hybrid model is based on Fourier series with 100 harmonics while the FEM is based on an air-gap discretization with 730 element over $2 \pi$.

Moreover, for a given rotor position, the torque-current curves are calculated for a wide range of the supply current. 


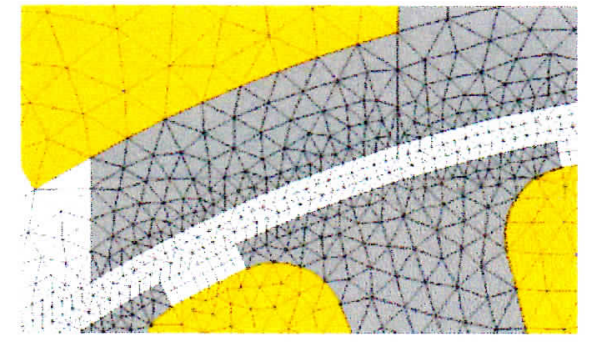

Fig. 4. Mesh of the machine in the corresponding 2-D FE model.

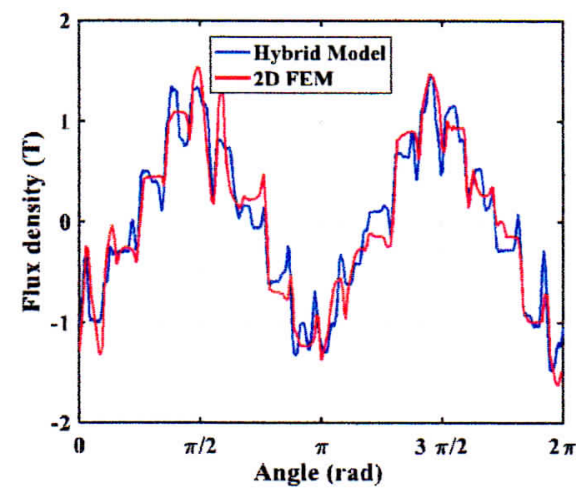

Fig. 5. Air-gap flux density waveforms over one period.

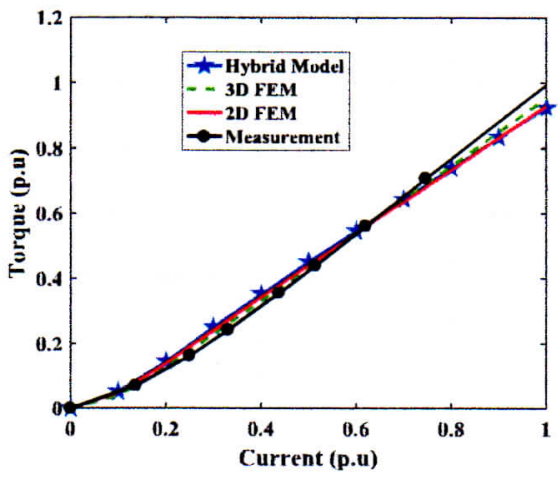

Fig. 6. Torque evolution for a given rotor position and several current values.

The high value of the current is characterized by a very high level of saturation and armature reaction. The comparison is performed between the presented hybrid model, 2-D and 3-D FEM and experimental measurements. The four torque-current curves are plotted in Fig. 6 in p.u. We note that the hybrid model and 2-D FEM give very similar results which prove the accuracy of the model for a wide range of the current.

There is a very slight difference between the results of 2-D and 3-D FEM due to the consideration of the 3-D effects by correcting factor in the 2-D FEM, as described in [7]. The agreement with experimental results validates all the models, and especially the proposed hybrid model.

Regarding the CPU time, using an Intel Xeon at $2.4 \mathrm{GHz}$ the hybrid model takes $\sim 2.5 \mathrm{~s}$, while the 2 -D FEM takes $\sim 36 \mathrm{~s}$ and 3-D FEM takes $\sim 8 \mathrm{~min}$ for each operation point.

Considering the rotor position in the MMFs calculation with field model, the torque is calculated for several rotor positions over one pole pitch (Fig. 7) with both hybrid and 2-D FEM.

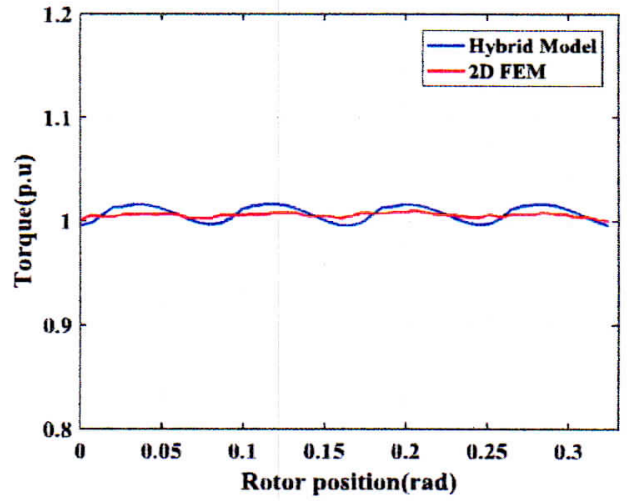

Fig. 7. Torque-position curve in highly saturated conditions.

Once again, a really good agreement between the two models is observed. This is not the case for classical RN models.

Then, we can highlight the advantages of the proposed hybrid model:

1) same accuracy and precision as 2-D or 3-D FEM;

2) low CPU time thanks to reduction of air-gap elements;

3) easier implementation than classical $\mathrm{RN}$ models accounting for the rotation (using only one air-gap reference point $P_{0}$ ).

\section{CONCLUSION}

In this paper, a hybrid model based on the coupling between $\mathrm{RN}$ and the resolution of the Laplace equation is developed and tested on a dc machine. The accuracy of the coupling using air-gap MMFs is validated by an experimental result as well as by 2-D and 3-D FEM. This type of model allows both simplifying the rotation modeling and, at the same time, makes the model robust using the method of MMF coupling. The accuracy of the model and its fastness make it of high interest to be used in an optimization process. Indeed, the coupling by MMFs allows us to have a very high robust model adaptable to geometry changes in a wide range of variation.

\section{REFERENCES}

[1] T. Lubin, S. Mezani, and A. Rezzoug, "Analytical computation of the magnetic field distribution in a magnetic gear," IEEE Trans. Magn., vol. 46, no. 7, pp. 2611-2621, Jul. 2010.

[2] A. Abdel-Razek, J. Coulomb, M. Feliachi, and J. Sabonnadiere, "The calculation of electromagnetic torque in saturated electric machines within combined numerical and analytical solutions of the field equations," IEEE Trans. Magn., vol. 17, no. 6, pp. 3250-3252, Nov. 1981.

[3] M. A. Tsili, A. G. Kladas, P. S. Georgilakis, A. T. Souflaris, and D. G. Paparigas, "Geometry optimization of magnetic shunts in power transformers based on a particular hybrid finite-element boundaryelement model and sensitivity analysis," IEEE Trans. Magn., vol. 41, no. 5, pp. 1776-1779, May 2005.

[4] E. Ilhan, B. L. J. Gysen, J. J. H. Paulides, and E. A. Lomonova, "Analytical hybrid model for flux switching permanent magnet machines," IEEE Trans. Magn., vol. 46, no. 6, pp. 1762-1765, Jun. 2010.

[5] Y. Laoubi, M. Dhifli, G. Verez, Y. Amara, and G. Barakat, "Open circuit performance analysis of a permanent magnet linear machine using a new hybrid analytical model," IEEE Trans. Magn., vol. 51, no. 3, pp. 1-4, Mar. 2015.

[6] T. Lubin, S. Mezani, and A. Rezzoug, "Exact analytical method for magnetic ficld computation in the air gap of cylindrical clcctrical machines considering slotting effects," IEEE Trans. Magn., vol. 46, no. 4, pp. 1092-1099, Apr. 2010.

17| R. Andreux, J. Fontchastagncr, N. Takorahcl, and N. I abhe, " $\Lambda$ fast finitc element model taking into account 3-D effects for the optimal design of micro-hybrid starters," IEEE Trans. Magn., vol. 50, no. 5, pp. 1-8, May 2014. 